\title{
Healthy worker effect and changes in respiratory symptoms and lung function in hairdressing apprentices
}

\author{
Y Iwatsubo, M Matrat, P Brochard, J Ameille, D Choudat, F Conso, D Coulondre, R Garnier, \\ C Hubert, F Lauzier, M C Romano, J C Pairon
}

Occup Environ Med 2003;60:831-840

See end of article for authors' affiliations

\section{Correspondence to:}

Prof. J C Pairon, CHI

Créteil, 40 avenue de

Verdun, 94010 Créteil

Cedex, France;

jc.pairon@chicreteil.fr

Accepted

17 December 2002

\begin{abstract}
Aims: To compare the prevalence and incidence of respiratory symptoms and lung function values between hairdressing apprentices and office apprentices.

Methods: A total of 322 hairdressing apprentices and 277 office apprentices (controls) were studied. Two cross sectional surveys were conducted in 1994 and 1996/97 with longitudinal follow up for a subgroup of apprentices (191 hairdressing apprentices and 189 office apprentices).

Results: In the initial phase, the prevalence of respiratory symptoms was significantly lower among hairdressing apprentices than among office apprentices. Lung function test results showed significantly higher values for hairdressing apprentices. Non-specific bronchial reactivity was similar in the two groups. In the final phase, results for respiratory symptoms were similar. The incidence of respiratory symptoms was not significantly different between hairdressing apprentices and office apprentices. Subjects who dropped out had lower values for FVC and $\mathrm{FEV}_{1}$ in the initial phase than those who completed the final phase. There was a significant deterioration of $\mathrm{FEV}_{1}$ and $\mathrm{FEF}_{25-75 \%}$ in hairdressing apprentices compared to office apprentices. There was a link between atopy and the incidence of most of the respiratory symptoms (day/night cough, wheezing, dyspnoea, mucosal hyperresponsiveness) and between smoking and the incidence of bronchial hyperreactivity. There was no significant correlation between change in lung function tests and specific hairdressing activities reported at the end of the apprenticeship or with environmental working conditions in hairdressing salons.

Conclusions: Although a healthy worker effect can be suspected, results showed a significant deterioration of baseline values of lung function tests in the hairdressing apprentice group. However, no clear link was shown between change in lung function tests and specific parameters of occupational activities.
\end{abstract}

$\mathrm{H}$ airdressing involves exposure to several chemicals known to be irritating or allergenic that can cause dermatological or respiratory disorders. In the study by Ameille and colleagues, ${ }^{1}$ based on the data collected in the Observatoire National des Asthmes Professionnels, hairdressers seemed to be at high risk of developing occupational asthma in France. The observed prevalence of respiratory diseases among hairdressers varies between $5 \%$ and $25 \% .^{2-4}$ The range of frequencies reported in previous studies could be due to methodological differences, such as study population, variations in the definition of respiratory disorders, and in the type and method of collection of health parameters (questionnaire, lung function). Although few studies have investigated the respiratory health of hairdressing apprentices, it has been suggested in other groups of apprentices exposed to allergens or metalworking fluids that respiratory disorders may occur soon after starting the apprenticeship. ${ }^{5-7}$ We therefore decided to study respiratory disorders in hairdressing apprentices and to compare their state of health to that of office apprentices not exposed to irritating or allergenic agents during their apprenticeship. This study comprised two cross sectional phases at the beginning and during the last months of apprenticeship. Some of the subjects participated in both phases of the study. The originality of our approach concerns the fact that this study was performed in apprentices and allowed prospective data collection on health parameters with concomitant evaluation of working conditions.

We present the prevalence of respiratory symptoms and the lung function values assessed in each cross sectional phase of the study, and the longitudinal results focusing on the incidence of respiratory symptoms and the change in lung function tests in hairdressing and office apprentices during a three year follow up, with specific attention to certain occupational tasks.

\section{SUBJECTS AND METHODS Study group}

The study population comprised hairdressing apprentices attending a vocational training school situated in Paris, France (Centre de formation d'apprentis A. Croisat) in their first year of training in 1994. All 322 apprentices present in 1994 were invited to participate in the initial phase of the study. The hairdressing apprenticeship usually consists of a three year programme, but some apprentices complete their training in two years. The apprentices were interviewed by the occupational physicians in charge of these apprentices and a physical examination was performed. In the two phases of the study, all participants were invited to undergo respiratory function tests. Follow up was scheduled for the second year and a final phase was planned before the end of training (final phase). During the study follow up period, vocational training was extended to provide places for apprentices who had begun their apprenticeship in another training centre. Another 89 hairdressing apprentices without an initial examination were therefore included in the final phase of the study.

\footnotetext{
Abbreviations: BHR, bronchial hyperresponsiveness; MHR, mucosal hyperresponsiveness; FVC, forced vital capacity; $\mathrm{FEV}_{1}$, forced expired volume in one second; $\mathrm{FEF}_{25-75 \%}$, forced expiratory flow $25-75 \%$; OR, odds ratio; $\mathrm{Cl}$, confidence interval
} 
Main messages

- A strong self selection towards respiratory health is suspected among hairdressing apprentices at the beginning of the apprenticeship.

- Although a healthy worker effect was suspected, hairdressing apprentices had a deterioration of baseline lung function tests during a three year follow up, in comparison with office apprentices.

- The incidence of non-specific bronchial hyperresponsiveness tended to be higher in hairdressing apprentices than in office apprentices.

- No specific hairdressing activity was clearly related to deterioration of lung function.

\section{Control group}

The control group was selected with a roughly similar gender, age, and socioeconomic category distribution. The control group consisted of office apprentices (secretaries and accountants) attending one of 10 vocational training schools situated in the Val de Marne Department close to Paris in their first year of training in 1994. This category of subjects was selected as controls as they are not exposed to irritating or allergenic agents during their apprenticeship. The usual duration of an office apprenticeship is two years. The total number of apprentices in 1994 was 277. Follow up was scheduled at the end of their training. As for hairdressing apprentices, all office apprentices present at the end of the study were invited to participate in the final phase, whether or not they had participated in the initial phase. An additional 61 office apprentices without an initial examination were therefore included in the final phase of the study.

\section{Questionnaire}

An occupational physician questioned the hairdressing apprentices during the occupational medicine examination held during the first months of apprenticeship. Similarly, a school physician interviewed the office apprentices.

A standardised questionnaire (French version derived from the British Medical Research Council (MRC) questionnaire for respiratory symptoms) was used to collect information about the presence of respiratory symptoms, smoking habits, medical history of atopy, and occupational activity during the past 12 months. The hairdressing apprentices were also asked about the frequency of different hairdressing activities: shampoo, permanent waves (involving exposure to thioglycolate, etc), dyeing (involving exposure to various dyeing agents including paraphenyldiamine, henna, etc), bleaching (involving exposure to persulphates), and hair cutting. The findings of a standard clinical examination were also recorded. Data were collected during the same period of the year in both groups for the initial phase (September 1994 to February 1995 for hairdressing apprentices and October 1994 to March 1995 for office apprentices).

The present report focuses on respiratory symptoms and lung function. The following respiratory symptoms were chosen from the data collected in the questionnaire: cough in the morning, cough during the day or night, sputum, wheezing, wheezing with dyspnoea, symptoms suggestive of non-specific mucosal hyperresponsiveness (MHR), defined in this study as the presence of one or more of the following symptoms: fit of coughing, sneezing or runny nose, eye symptoms, and acute dyspnoea.

\section{Lung function}

Lung function was measured by expiratory flow-volume curves performed with a spirometer (Fukuda Sangyo, Tokyo,
Policy implications

- Respiratory health surveillance should be reinforced in hairdressers and specific studies should be conducted to study workplace chemical exposures.

- Specific attention should be paid to the lung function of apprentices training in occupations known to be associated with respiratory disorders.

- The overall level of exposure to chemicals in hairdressing salons needs to be minimised.

Japan). Trained operators conducted the tests for hairdressing apprentices and office apprentices. They were trained by three senior instructors (JA, DC, JCP). The manoeuvre was repeated 3-5 times (if the first three curves showed poor reproducibility) to select the best curve (best value of $\mathrm{FEV}_{\mathrm{I}}+\mathrm{FVC}$ ). Only subjects with a variation in $\mathrm{FEV}_{1}+\mathrm{FVC}$ less than $5 \%$ were included in the study. The following parameters were recorded: forced vital capacity $(\mathrm{FVC})$, forced expired volume in one second $\left(\mathrm{FEV}_{\mathrm{l}}\right), \mathrm{FEV}_{\mathrm{l}} /$ FVC, and forced expiratory flow 25-75\% $\left(\mathrm{FEF}_{25-75 \%}\right)$. The relative values were calculated using the reference values established by Knudson and colleagues. ${ }^{8}$

\section{Methacholine challenge}

A methacholine challenge was performed with an aerosol nebuliser (Mediprom FDC88, Paris, France) which delivered successively increasing doses of methacholine. The methacholine concentration was $2.5 \mathrm{mg} / \mathrm{ml}$. Three increasing doses were delivered to subjects with no history of asthma: $100 \mu \mathrm{g}$, $500 \mu \mathrm{g}$, and $1500 \mu \mathrm{g}$. If the subject reported a history of asthma, the protocol included four doses of methacholine: $50 \mu \mathrm{g}, 200 \mu \mathrm{g}, 500 \mu \mathrm{g}$, and $1500 \mu \mathrm{g}$. A flow-volume curve was performed after each inhalation of methacholine. Because methacholine challenge was performed in schools, it was decided to interrupt the test if a $15 \%$ decrease in $\mathrm{FEV}_{1}$ was observed compared to the baseline test.

Methacholine challenge was not performed if the baseline $\mathrm{FEV}_{1} / \mathrm{FVC}$ ratio was less than $75 \%$ or if the student reported an asthma attack during the previous six months. Two senior investigators (JA, JCP) checked the quality of flow-volume curves. The methacholine challenge was considered to be positive when a $15 \%$ fall in $\mathrm{FEV}_{1}$ was observed and the subject was classified as having bronchial hyperresponsiveness (BHR). Bronchial responsiveness was also evaluated by the methacholine dose-response slope, defined by the percent decline in $\mathrm{FEV}_{1}$ divided by the final cumulative dose of methacholine administered (expressed in $\mu \mathrm{g}$ ), as suggested by $\mathrm{O}^{\prime}$ Connor and colleagues. ${ }^{9}$

\section{Occupational condition measures}

A hairdressing training centre instructor studied the work conditions in various salons attended by hairdressing apprentices during their practical training. The information collected concerned the surface area, type of floor and walls (with or without carpet), presence of a technical area, and presence of mechanical ventilation. This type of workplace description was obtained for 161 salons.

\section{Statistical analysis}

The prevalence of respiratory symptoms and baseline lung function values were compared between hairdressing apprentices and office apprentices. We used $\chi^{2}$ tests to analyse respiratory symptoms and BHR, and Student's $t$ tests to analyse baseline lung function and the methacholine doseresponse slope. The methacholine dose-response slope was 
expressed by the $\log$ transformed value [log(slope+0.02)]. Smoking status, age, gender, and atopy were considered to be potential confounding factors. Atopy was defined by a positive answer to one of the following questions: "Do you have a past medical history of asthma?"; "Do you have a past medical history of allergic rhinitis?"; "Do you have a medical history of atopic dermatitis?".

The determinants of respiratory symptoms and lung function were examined at each cross sectional phase of the study from the information provided in the questionnaire: group status (hairdressing or office apprentices), smoking status, atopy, gender, age.

For the determinants of respiratory symptoms, we used logistic regression analyses with forward stepwise selection of variables. The "group" variable was always forced into the model. The determinants of lung function were examined using multiple linear regression models with forward stepwise selection of variables. As sex and age were taken into account in calculation of predicted values, we did not examine these two variables for baseline lung function parameters. Age and gender were examined for the methacholine dose-response slope.

The incidence of respiratory symptoms at the final phase among those subjects who did not report symptoms at the initial phase was compared between hairdressing apprentices and office apprentices. The difference between the percentage of predicted value in 1997 and the percentage of predicted value in 1994 reflected the change in lung function.

We used $\chi^{2}$ tests to analyse the incidence of respiratory symptoms and BHR and Student's $t$ tests to analyse changes in lung function and changes in the methacholine doseresponse slope. The change in the methacholine doseresponse slope was calculated by the difference between the log transformed value of the slopes at the final phase and at the initial phase. We used a Student's $t$ test or one way analysis of variance to analyse changes in lung function according to working conditions.

Predictors of the incidence of respiratory symptoms and change in lung function tests were identified from the data collected by the questionnaire at the initial phase: group status (hairdressing or office apprentices, smoking status, atopy, gender, age).

Multivariate analyses for predictors of the incidence of respiratory symptoms and BHR were carried out using logistic regression with forward stepwise selection of the variables. Predictors of change in lung function were examined by multiple regression models with forward stepwise selection of variables.

Group status was a fixed parameter of the model in all multivariate analyses performed. SAS software was used for statistical analysis. ${ }^{10}$

Each student was informed about the objectives of the study and written consent was obtained from the participant or his/her family when under the age of 18 years. This study was approved by a teaching hospital ethics committee (Hôpital Henri Mondor).

\section{RESULTS}

\section{Participation}

Figure 1 summarises the participation rates at different steps of the protocol.

\section{Initial phase (in 1994)}

A total of $297(92 \%)$ of the 322 hairdressing apprentices present participated in the questionnaire survey and 239 subjects $(74 \%)$ participated in the lung function tests. For office apprentices, 248 of the 277 eligible subjects participated in the questionnaire survey (89\%) and $124(45 \%)$ participated in the lung function tests.

\section{Final phase (in 1996 or 1997)}

A total of 191 of the hairdressing apprentices who participated in the initial examination completed the final examination, which also included 89 additional subjects for the questionnaire survey. A total of 280 questionnaires and 218 lung function tests were available for the final examination. Among the office apprentices, 250 questionnaires and 138 lung function tests were available.

\section{Longitudinal survey}

A total of 191 hairdressing apprentices completed the questionnaires and 119 completed the lung function tests (67 had two years of training and 124 had three years of training), while 189 office apprentices completed the questionnaires and 76 completed the lung function tests.

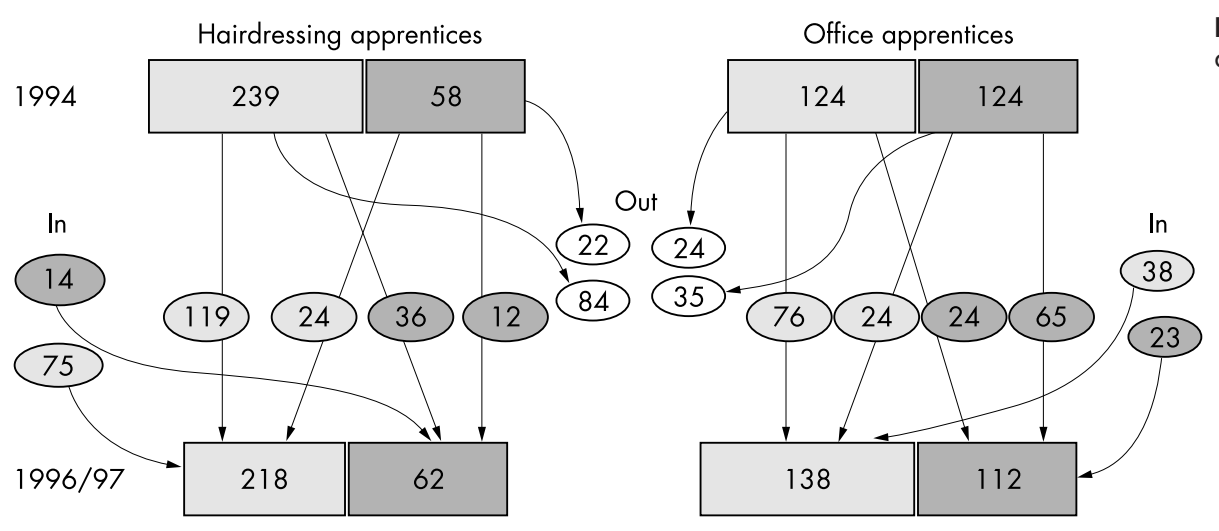

Figure 1 Plan of the medical survey of apprentices.

$Q+L F$ Participation in medical questionnaire and lung function tests

$Q$ only Participation in medical questionnaire only

In: subjects who did not participate in the initial phase

Out: subjects who did not participate in the final phase 
Table 1 Main characteristics, respiratory symptoms, and respiratory function in hairdressing apprentices and office apprentices in the two phases of the study

\begin{tabular}{|c|c|c|c|c|c|c|}
\hline & \multicolumn{2}{|l|}{ Initial phase } & \multirow[b]{2}{*}{$p$ value } & \multicolumn{2}{|l|}{ Final phase } & \multirow[b]{2}{*}{$p$ value } \\
\hline & $\begin{array}{l}\text { Hairdressing } \\
\text { apprentices } \\
n=297\end{array}$ & $\begin{array}{l}\text { Office apprentices } \\
n=248\end{array}$ & & $\begin{array}{l}\text { Hairdressing } \\
\text { apprentices } \\
n=280\end{array}$ & $\begin{array}{l}\text { Office apprentices } \\
n=250\end{array}$ & \\
\hline Gender (\% females) & 84.8 & 87.9 & 0.30 & 88.6 & 89.6 & 0.70 \\
\hline Age $(y)$, mean $(S D)$ & $17.1(1.3)$ & $16.8(0.9)$ & 0.0004 & $19.0(1.1)$ & $18.1(1.0)$ & $<0.0001$ \\
\hline Height $(\mathrm{cm})$, mean (SD) & $163.8(7.8)$ & $164.2(7.3)$ & 0.54 & $164.0(7.0)$ & $165.8(7.9)$ & 0.03 \\
\hline \multicolumn{7}{|l|}{ Smoking habits } \\
\hline Non-smoker (\%) & 44.8 & 62.5 & $<0.0001$ & 38.2 & 60.1 & $<0.0001$ \\
\hline Current or ex-smoker(\%) & 55.3 & 37.5 & & 61.8 & 39.9 & \\
\hline Cig/day, mean (SD) & $9.5(6.6)$ & $8.9(6.0)$ & 0.48 & $11.1(5.1)$ & $9.2(6.3)$ & 0.02 \\
\hline Atopy $^{*}(\%)$ & 20.2 & 24.6 & 0.22 & & & \\
\hline \multicolumn{7}{|l|}{ Symptoms } \\
\hline Morning cough (\%) & 2.7 & 6.5 & 0.03 & 3.6 & 4.4 & 0.63 \\
\hline Cough day/night (\%) & 3.0 & 12.1 & $<0.0001$ & 3.2 & 8.8 & 0.006 \\
\hline Morning sputum (\%) & 0.7 & 4.0 & 0.008 & 1.4 & 1.2 & 0.82 \\
\hline Wheezing (\%) & 8.8 & 19.8 & 0.0002 & 10.0 & 18.8 & 0.004 \\
\hline Dyspnoea with wheezing (\%) & 7.7 & 12.5 & 0.06 & 6.1 & 11.2 & 0.03 \\
\hline $\mathrm{MHR}+(\%)$ & 25.3 & 42.7 & $<0.0001$ & 29.6 & 40.8 & 0.007 \\
\hline Work related MHR (\%) & & & & 6.1 & 2.8 & 0.07 \\
\hline $\begin{array}{l}\text { Work related wheezing and/or dyspnoea } \\
\text { according to the occupational physician (\%) }\end{array}$ & & & & 3.6 & 0 & 0.003 \\
\hline Respiratory function $\ddagger$ & $(n=239)$ & $(n=124)$ & & $(n=218)$ & $(n=138)$ & \\
\hline$\% \mathrm{FVC}$, mean (SD) & $102.7(11.8)$ & $100.7(14.1)$ & 0.15 & $102.4(10.9)$ & $100.1(12.8)$ & 0.07 \\
\hline$\% \mathrm{FEV}_{1}$, mean (SD) & $103.1(11.7)$ & $100.0(12.9)$ & 0.02 & $101.8(10.9)$ & $99.8(12.0)$ & 0.10 \\
\hline $\mathrm{FEV}_{1} / \mathrm{FVC}$, mean $(\mathrm{SD})$ & $89.3(5.6)$ & $88.5(5.7)$ & 0.21 & $88.7(5.1)$ & $89.1(6.0)$ & 0.54 \\
\hline 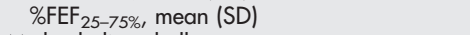 & $100.5(21.0)$ & $95.8(20.1)$ & 0.04 & $97.4(19.6)$ & $98.9(22.3)$ & 0.50 \\
\hline \multicolumn{7}{|l|}{ Methacholine challenge§ } \\
\hline BHR $\left(15 \%\right.$ decrease in $\left.\mathrm{FEV}_{1}\right)(\%)$ & 33.3 & 31.9 & 0.79 & 35.3 & 24.8 & 0.04 \\
\hline $\log ($ methacholine slope +0.02$)$, mean (SD) & $-1.51(0.23)$ & $-1.50(0.26)$ & 0.74 & $-1.51(0.26)$ & $-1.54(0.20)$ & 0.22 \\
\hline $\begin{array}{l}\text { *Atopy defined by positive medical history of as as } \\
\text { †MHR: mucosal hyperresponsiveness, defined in } \\
\text { symptoms, and acute dyspnoea. } \\
\text { tPercentage of the reference values established } \\
\text { \$Only } 234 \text { hairdressing apprentices and } 116 \text { off } \\
\text { completed the methacholine challenge. } \\
\text { "Methacholine dose-response slope, defined by }\end{array}$ & $\begin{array}{l}\text { na or allergic } r \\
\text { s study as the pi } \\
\text { Knudson and } \\
\text { apprentices at } t\end{array}$ & $\begin{array}{l}\text { ce of one or more } \\
\text { gues. }{ }^{8} \\
\text { itial phase and } 20\end{array}$ & hairdress & $\begin{array}{l}\text { atitis. } \\
\text { ymptoms: fit }\end{array}$ & $\begin{array}{l}\text { ghing, sneezing } \\
\text { office apprentices }\end{array}$ & $\begin{array}{l}\text { ny nose, eye } \\
\text { final phase }\end{array}$ \\
\hline
\end{tabular}

\section{Main characteristics of the population}

Initial phase (1994)

Female subjects represented more than $80 \%$ of the population in both groups (table 1). The mean age was 17.1 ( 1.3 ) years for hairdressing apprentices and 16.8 (0.9) years for office apprentices $(p<0.001)$. The frequency of smokers was significantly higher in the hairdressing group than in the office group ( $p<0.001)$. The frequency of atopy at the initial examination was not significantly different between the two groups. Office apprentices presented higher frequencies for

Table 2 Incidence of respiratory symptoms and change in lung function tests between the initial and final phases in hairdressing and office apprentices

\begin{tabular}{|c|c|c|c|}
\hline & Hairdressing apprentices & Office apprentices & $\mathrm{p}$ value \\
\hline Symptoms & $(n=191)$ & $(n=189)$ & \\
\hline Morning cough (\%) & 2.7 & 3.3 & 0.71 \\
\hline Cough day/night (\%) & 4.3 & 4.7 & 0.84 \\
\hline Morning sputum (\%) & 1.6 & 1.1 & 0.68 \\
\hline Wheezing (\%) & 10.0 & 11.5 & 0.66 \\
\hline Dyspnoea with wheezing (\%) & 3.9 & 6.6 & 0.26 \\
\hline $\mathrm{MHR}^{*}(\%)$ & 26.2 & 26.1 & 0.99 \\
\hline Lung function tests & $(n=119)$ & $(n=76)$ & \\
\hline$\Delta \mathrm{FVC}$, mean $(\mathrm{SD}) \dagger$ & $-1.0(7.4)$ & $0.8(7.4)$ & 0.09 \\
\hline$\Delta \mathrm{FEV}_{1}$, mean $(\mathrm{SD})$ & $-2.5(8.4)$ & $0.0(7.4)$ & 0.03 \\
\hline$\Delta \mathrm{FEV}_{1} / \mathrm{FVC}$, mean (SD) & $-1.3(4.1)$ & $-0.6(3.7)$ & 0.29 \\
\hline$\Delta \mathrm{FEF}_{25-75 \%}$, mean $(\mathrm{SD})$ & $-4.8(14.6)$ & $-0.2(15.9)$ & 0.04 \\
\hline \multicolumn{4}{|l|}{ Methacholine challenge } \\
\hline $\operatorname{BHR}\left(15 \%\right.$ decrease in $\left.\mathrm{FEV}_{1}\right)(\%)$ & 21.6 & 14.9 & 0.36 \\
\hline Change in methacholine slope, $\ddagger$ mean (SD) & $0.044(0.19)$ & $-0.025(0.26)$ & 0.04 \\
\hline
\end{tabular}

${ }^{*}$ MHR: mucosal hyperresponsiveness, defined in this study as the presence of one or more of the following symptoms: fit of coughing, sneezing or runny nose, eye symptoms, and acute dyspnoea.

$\dagger \Delta: \%$ predicted at the final phase $-\%$ predicted at the initial phase.

$\ddagger$ Methacholine dose-response slope, defined by the percent decline in $\mathrm{FEV}_{1}$ divided by the final cumulative dose of methacholine administered. Change in methacholine slope defined as log(slope +0.02$)$ at the final phase $\log ($ slope +0.02$)$ at the initial phase. 
Table 3 Determinants of respiratory symptoms and BHR during methacholine challenge in the initial and final cross sectional phases and predictors of the incidence of respiratory symptoms of the longitudinal survey: logistic regression analyses*

\begin{tabular}{|c|c|c|c|c|c|c|}
\hline & $\begin{array}{l}\text { Morning cough } \\
\text { OR }(95 \% \mathrm{Cl}) \S\end{array}$ & $\begin{array}{l}\text { Day or night cough } \\
\text { OR }(95 \% \text { CI) }\end{array}$ & $\begin{array}{l}\text { Wheezing } \\
\text { OR }(95 \% \mathrm{CI})\end{array}$ & $\begin{array}{l}\text { Dyspnoea } \\
\text { OR }(95 \% \mathrm{Cl})\end{array}$ & $\begin{array}{l}\text { MHR† } \\
\text { OR }(95 \% \mathrm{Cl})\end{array}$ & $\begin{array}{l}\text { BHR } \ddagger \\
\text { OR }(95 \% \mathrm{Cl})\end{array}$ \\
\hline \multicolumn{7}{|l|}{ Initial phase } \\
\hline $\begin{array}{l}\text { Hairdressing apprentices } \\
\text { v office apprentices }\end{array}$ & $0.3(0.1$ to 0.8$)$ & $0.2(0.1$ to 0.4$)$ & $0.3(0.2$ to 0.6$)$ & $0.5(0.3$ to 1.1$)$ & $0.4(0.3$ to 0.6$)$ & $1.1(0.7$ to 1.9$)$ \\
\hline Gender (female $v$ male) & - & - & - & $0.4(0.2$ to 1.0$)$ & - & $2.3(1.1$ to 4.8$)$ \\
\hline $\begin{array}{l}\text { Current or ex-smokers } \\
v \text { non-smokers }\end{array}$ & $9.3(2.7$ to 32.4$)$ & 6.2 (2.7 to 14.3 ) & 2.0 (1.1 to 3.5$)$ & & 1.7 (1.1 to 2.5$)$ & - \\
\hline Atopy & $4.2(1.8$ to 10.1$)$ & $3.9(1.9$ to 8.0$)$ & 9.6 (5.5 to 16.7$)$ & 34.4 (14.9 to 79.7$)$ & 5.9 (3.7 to 9.3 ) & $2.3(1.3$ to 4.1$)$ \\
\hline \multicolumn{7}{|l|}{ Final phase } \\
\hline $\begin{array}{l}\text { Hairdressing apprentices } \\
\text { v office apprentices }\end{array}$ & $0.6(0.2$ to 1.4$)$ & $0.3(0.2$ to 0.8$)$ & $0.4(0.2$ to 0.6$)$ & $0.5(0.3$ to 1.0$)$ & 0.5 (0.4 to 0.8$)$ & 1.6 (1.0 to 2.6$)$ \\
\hline Gender (female $v$ male) & - & - & - & - & - & $3.6(1.4$ to 9.5$)$ \\
\hline $\begin{array}{l}\text { Current or ex-smokers } \\
v \text { non-smokers }\end{array}$ & 6.8 (1.9 to 23.8 ) & - & 2.6 (1.5 to 4.5$)$ & - & $1.6(1.1$ to 2.4$)$ & - \\
\hline \multicolumn{7}{|l|}{ Longitudinal survey } \\
\hline $\begin{array}{l}\text { Hairdressing apprentices } \\
v \text { office apprentices }\end{array}$ & 0.7 (0.2 to 2.3 ) & $0.8(0.3$ to 2.4$)$ & $0.8(0.4$ to 1.7$)$ & $0.6(0.2$ to 1.6$)$ & $0.9(0.5$ to 1.7$)$ & $1.4(0.5$ to 3.9$)$ \\
\hline $\begin{array}{l}\text { Current or ex-smokers } \\
v \text { non-smokers }\end{array}$ & - & - & - & - & - & $3.0(1.1$ to 8.2$)$ \\
\hline Atopy & - & $4.6(1.6$ to 13.4$)$ & $7.0(3.2$ to 15.1$)$ & $4.6(1.7$ to 12.6$)$ & $2.6(1.1$ to 5.8$)$ & ** \\
\hline
\end{tabular}

Initial phase: 297 hairdressing apprentices, 248 office apprentices; final phase: 280 hairdressing apprentices, 250 office apprentices; for BHR, 234 hairdressing apprentices and 116 office apprentices at the initial phase and 204 hairdressing apprentices and 129 office apprentices at the final phase. Longitudinal survey: 191 hairdressing apprentices and 189 office apprentices; for BHR.

*Variables examined in the models are: group status (fixed variable), gender, age, smoking status, atopy. As age did not have any significant effect on any of the respiratory symptoms studied, it was removed from the table. Similarly, gender was removed from the table in the longitudinal survey.

-, variables not entered in the model.

TMHR: mucosal hyperresponsiveness defined in this study as the presence of one or more of the following symptoms: fit of coughing, sneezing or runny nose, eye symptoms, and acute dyspnoea.

$\ddagger B H R: 15 \%$ fall in $\mathrm{FEV}_{1}$ during the methacholine challenge test.

§Adjusted odds ratio and $95 \%$ confidence interval.

-Atopy defined by positive medical history of asthma or allergic rhinitis or medical history of atopic dermatitis. Information on this parameter was missing for 89 hairdressing apprentices and 61 office apprentices participating only in the final phase. Therefore, this parameter was not examined in the logistic regression models of the final phase.

${ }^{* *}$ Atopy not taken into account as no subject with atopy at the initial phase presented BHR at the final phase.

all respiratory symptoms considered, as well as the reported frequency of symptoms suggestive of MHR. Lung function values were lower in office apprentices with a significant difference for the relative values of $\mathrm{FEV}_{1}$ and $\mathrm{FEF}_{25-75 \%}$. The frequency of BHR, as assessed by the methacholine challenge, was not significantly different between the two groups.

\section{Final phase}

A similar pattern of distribution of clinical and baseline lung function values was observed at the initial phase and at the final phase (table 1), although a large proportion of the participants in this phase were not the same as those participating in the initial phase (fig 1). The frequency of subjects reporting symptoms suggestive of MHR was always higher among office apprentices than among hairdressing apprentices. This percentage was higher than at the initial phase in hairdressing apprentices and slightly lower in office apprentices. Work relatedness of wheezing and/or dyspnoea was reported by the occupational physician in $3.6 \%$ of hairdressing apprentices and $0 \%$ of office apprentices $(\mathrm{p}<0.001)$.

The main finding was the percentage of subjects with a $15 \%$ fall in $\mathrm{FEV}_{1}$ on the methacholine challenge test, which was significantly higher among hairdressing apprentices than among office apprentices in the final phase.

\section{Incidence of respiratory symptoms and change in lung function tests}

Table 2 shows the incidence rates of respiratory symptoms and the change in lung function tests in the two groups. No significant difference was observed between the two groups for the incidence of respiratory symptoms. In contrast, significant differences in the change in $\mathrm{FEV}_{1}$ and $\mathrm{FEF}_{25-75 \%}$ were observed between the two groups, as negative changes were observed in hairdressing apprentices, suggesting deterioration of lung function in this group. Although the incidence of BHR was higher among hairdressing apprentices than among office apprentices, the difference was not significant. The difference between methacholine slope at the final and initial phase was greater among hairdressing apprentices than among office apprentices $(p=0.04)$.

\section{Determinants of respiratory symptoms and lung function Initial phase}

For all respiratory symptoms, the OR for hairdressing apprentices was less than 1 (table 3). Multivariate analysis did not show any significant effect of group status for BHR on the methacholine challenge test. The other determinants of respiratory symptoms were smoking status with increased OR related to smoking (ex or current smokers) and the presence of atopy. Smoking status did not have any significant effect on baseline lung function values. In contrast, group status was significantly related to $\% \mathrm{FEV}_{1}$ and $\% \mathrm{FEF}_{25-75 \%}$, with higher values observed among hairdressing apprentices (table 4).

\section{Final phase}

Determinants of respiratory symptoms and lung function values were examined in the same way using information collected at the final phase. The results observed at this examination were similar to those observed at the initial phase for respiratory symptoms and BHR, as hairdressing apprentices presented fewer symptoms than office apprentices (table 3). In contrast, group status was no longer related to lung function (table 4). 


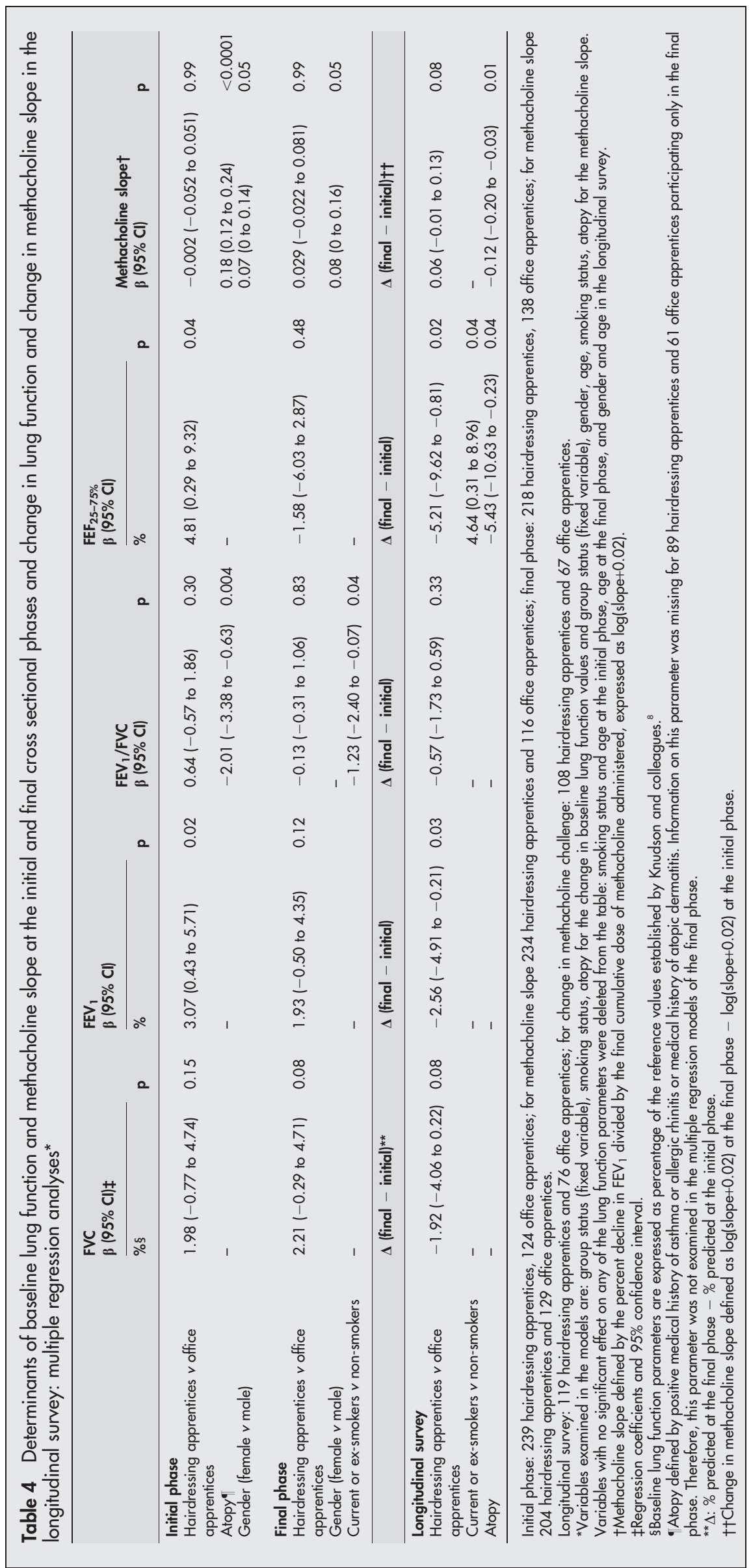

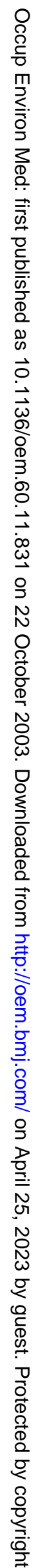


Table 5 Comparison of respiratory symptoms and lung function tests measured in the initial phase between participants and non-participants in the final phase

\begin{tabular}{|c|c|c|c|c|c|c|}
\hline & \multicolumn{2}{|c|}{ Hairdressing apprentices } & \multirow[b]{2}{*}{$p$ value } & \multicolumn{2}{|c|}{ Office apprentices } & \multirow[b]{2}{*}{ p value } \\
\hline & $\begin{array}{l}\text { Participants } \\
n=191\end{array}$ & $\begin{array}{l}\text { Drop outs } \\
n=106\end{array}$ & & $\begin{array}{l}\text { Participants } \\
n=189\end{array}$ & $\begin{array}{l}\text { Drop outs } \\
n=59\end{array}$ & \\
\hline Gender (\% females) & 88.5 & 78.1 & 0.02 & 91.0 & 78.0 & 0.007 \\
\hline Age $(y)$, mean (SD) & $17.0(1.0)$ & $17.4(1.7)$ & 0.006 & $16.7(1.0)$ & $17.0(0.8)$ & 0.05 \\
\hline \multicolumn{7}{|l|}{ Smoking habits } \\
\hline Non-smoker (\%) & 50.8 & 34.0 & 0.005 & 63.5 & 59.3 & 0.56 \\
\hline Current or ex-smoker (\%) & 49.2 & 66.0 & & 32.3 & 40.7 & \\
\hline Cig/day, mean (SD) & $8.8(6.4)$ & $10.4(6.8)$ & 0.08 & $7.6(4.9)$ & $12.8(7.3)$ & 0.0002 \\
\hline Atopy $(\%)$ & 16.2 & 27.4 & 0.02 & 22.2 & 32.2 & 0.12 \\
\hline \multicolumn{7}{|l|}{ Symptoms } \\
\hline Morning cough (\%) & 2.1 & 3.8 & 0.39 & 4.8 & 11.9 & 0.05 \\
\hline Cough day/night (\%) & 2.1 & 4.7 & 0.21 & 10.6 & 17.0 & 0.19 \\
\hline Morning sputum (\%) & 0.5 & 0.9 & 0.67 & 3.2 & 6.8 & 0.22 \\
\hline Wheezing (\%) & 5.8 & 14.2 & 0.01 & 16.9 & 28.8 & 0.05 \\
\hline Dyspnoea with wheezing (\%) & 5.8 & 11.3 & 0.09 & 11.1 & 17.0 & 0.24 \\
\hline ḾHR+ (\%) & 24.1 & 27.4 & 0.53 & 41.3 & 47.5 & 0.40 \\
\hline Work related MHR & 1.1 & 1.9 & 0.55 & 3.2 & 3.4 & 0.93 \\
\hline Lung function tests $¥$ & $(n=119)$ & $(n=120)$ & & $(n=76)$ & $(n=48)$ & \\
\hline$\%$ FVC, mean (SD) & $104.4(10.8)$ & $100.9(12.5)$ & 0.02 & $100.3(14.2)$ & $101.4(14.0)$ & 0.67 \\
\hline$\% \mathrm{FEV}_{1}$, mean $(\mathrm{SD})$ & $105.1(10.6)$ & $101.1(12.4)$ & 0.008 & $100.3(12.6)$ & $99.5(13.5)$ & 0.72 \\
\hline $\mathrm{FEV}_{1} / \mathrm{FVC}$, mean $(\mathrm{SD})$ & $89.7(5.4)$ & $88.9(5.8)$ & 0.26 & $89.3(5.9)$ & $87.3(5.1)$ & 0.04 \\
\hline$\% \mathrm{FEF}_{25-75 \% \text {, mean (SD) }}$ & $102.5(20.7)$ & $98.6(21.2)$ & 0.16 & $97.8(21.2)$ & $92.6(18.1)$ & 0.16 \\
\hline \multicolumn{7}{|l|}{ Methacholine challenge } \\
\hline BHR ( $15 \%$ decrease in FEV1) (\%) & 33.1 & 33.8 & 0.92 & 31.9 & 31.8 & 0.99 \\
\hline log(methacholine slope $\$+0.02)$, mean (SD) & $-1.53(0.22)$ & $-1.50(0.24)$ & 0.35 & $-1.50(0.29)$ & $-1.51(0.20)$ & 0.81 \\
\hline
\end{tabular}

\section{Longitudinal analysis}

Multivariate analyses showed that the incidence of several respiratory symptoms (day/night cough, wheezing, dyspnoea, MHR) was related to atopy, but not to occupational group (table 3). The incidence of BHR was significantly related to smoking habits (table 3). Hairdressing apprentices had a significantly greater risk of deterioration of baseline lung function tests during follow up (table 4).

As the subjects participating in the longitudinal study represented only a fraction of the initial group $(64 \%$ of hairdressing apprentices and $76 \%$ of office apprentices for the questionnaire study, and $50 \%$ of hairdressing apprentices and $61 \%$ of office apprentices for the lung function study), we compared the prevalence of respiratory symptoms and lung function parameters in subjects who participated in both phases of the study and in subjects who dropped out after the initial survey (table 5). Subjects who dropped out generally presented higher frequencies of respiratory symptoms in the two groups of apprentices and hairdressing apprentices who dropped out had lower values for several baseline lung function tests than those who participated in both phases.

\section{Working conditions}

Less than half of the salons had a specific ventilated technical area.

None of the work related factors examined (frequency of permanent waving, frequency of dyeing, frequency of bleaching, hairdressing salon surface area, presence of technical area, and mechanical ventilation) were related to change in lung function parameters in hairdressing apprentices (table 6).

\section{DISCUSSION}

This study, focusing on respiratory symptoms and lung function, showed that hairdressing apprentices were likely to be healthier than office apprentices, at least in terms of lung function. These results were found in the initial phase and in the final phase of the study. We expected to find no difference between the two groups at the beginning of apprenticeship, with possibly a higher incidence of respiratory symptoms among hairdressing apprentices than among office apprentices in the final phase. On the other hand, the significant correlation between atopic status and wheezing, dyspnoea, and mucous hyperresponsiveness at both phases of the study was only to be expected.

The longitudinal data in hairdressing apprentices compared to office apprentices, did not reveal any significant difference in the incidence of respiratory symptoms between the two groups. This could reflect denial by some hairdressing apprentices who like their occupation and did not want to leave their job. However, deterioration of lung function was observed in hairdressing apprentices compared to office apprentices. Lung function could probably be less biased than respiratory symptoms in this follow up study.

Certain methodological aspects of this study need to be discussed. In 1994, we obtained a relatively large participation rate in the two groups: $92 \%$ in hairdressing apprentices and $89 \%$ in office apprentices. Consequently, the study sample can be considered to be almost identical to the target population of these two types of apprentices.

Self selection bias of apprentices could have occurred when choosing their future occupation, or may have resulted from advice from the school physician. Apprentices with a history of allergic diseases or respiratory disorders could have chosen an occupation without exposure to irritating or allergenic agents. Such a selection bias favouring a healthy worker effect is more likely in apprentices exposed to sensitising materials with irritant properties (such as persulphates in hairdressing apprentices) than in apprentices exposed to sensitising materials with no such irritant properties (such as animal health technology or pastry making apprentices). On the other hand, people with a history of allergy could have 
Table 6 Relation between hairdressing activities and changes in baseline lung function parameters

\begin{tabular}{|c|c|c|c|c|c|c|c|c|c|c|c|c|c|c|c|}
\hline \multirow[b]{2}{*}{ Occupational factors (n) } & \multicolumn{3}{|l|}{$\Delta \mathrm{FVC}^{*}$} & \multicolumn{3}{|l|}{$\Delta \mathrm{FEV}_{1}{ }^{*}$} & \multicolumn{3}{|c|}{$\Delta \mathrm{FEV}_{1} / \mathrm{FVC} \boldsymbol{}$} & \multicolumn{3}{|c|}{$\Delta \mathrm{FEF}_{25-75 \%}{ }^{*}$} & \multicolumn{3}{|c|}{$\Delta$ methacholine slope } \\
\hline & Mean & SD & $p$ & Mean & SD & $p$ & Mean & SD & $p$ & Mean & SD & $p$ & Mean & SD & $p$ \\
\hline \multicolumn{16}{|l|}{ Permanent waves } \\
\hline$<1 /$ day (19) & -3.7 & 9.0 & \multirow{3}{*}{0.11} & -5.3 & 9.1 & \multirow{3}{*}{0.01} & -1.2 & 4.3 & \multirow{3}{*}{0.04} & -7.8 & 17.1 & \multirow{3}{*}{0.01} & 0.07 & 0.16 & \multirow{3}{*}{0.70} \\
\hline 1-4/day (74) & 0 & 7.5 & & 0.7 & 8.2 & & -0.6 & 4.2 & & -1.7 & 13.5 & & 0.03 & 0.20 & \\
\hline$\geqslant 5 /$ day $(26)$ & -2.0 & 4.8 & & -5.5 & 7.6 & & -3.0 & 3.5 & & -11.1 & 13.8 & & 0.06 & 0.18 & \\
\hline \multicolumn{16}{|l|}{ Dyeing } \\
\hline$<$ l/day (5) & -5.7 & 8.0 & \multirow{3}{*}{0.29} & -3.6 & 10.8 & \multirow{3}{*}{0.48} & 1.9 & 2.0 & \multirow{3}{*}{0.11} & -1.2 & 23.7 & \multirow{3}{*}{0.14} & 0.17 & 0.29 & \multirow{3}{*}{0.43} \\
\hline $1-4 /$ day (51) & -0.3 & 6.7 & & -1.4 & 8.1 & & -0.9 & 5.2 & & -2.0 & 16.0 & & 0.04 & 0.22 & \\
\hline$\geqslant 5 /$ day (63) & -1.2 & 7.8 & & -3.3 & 8.6 & & -1.8 & 3.1 & & -7.3 & 12.3 & & 0.04 & 0.16 & \\
\hline \multicolumn{16}{|l|}{ Bleaching } \\
\hline$<1 /$ day $(60)$ & -1.4 & 8.0 & \multirow{3}{*}{0.69} & -3.4 & 8.4 & \multirow{3}{*}{0.41} & -1.7 & 3.6 & \multirow{3}{*}{0.40} & -6.3 & 14.3 & \multirow{3}{*}{0.47} & 0.07 & 0.19 & \multirow{3}{*}{0.36} \\
\hline 1-5/day (49) & -0.3 & 6.6 & & -1.4 & 8.0 & & -0.6 & 4.9 & & -2.8 & 15.1 & & 0.02 & 0.20 & \\
\hline$\geqslant 5 /$ day $(10)$ & -1.8 & 7.4 & & -2.1 & 11.0 & & -1.4 & 3.1 & & -5.4 & 14.2 & & 0.02 & 0.11 & \\
\hline \multicolumn{16}{|l|}{ Surface area $\left(\mathrm{m}^{2}\right)$} \\
\hline$<38(30)$ & -1.5 & 5.5 & \multirow{4}{*}{0.70} & -2.9 & 6.6 & \multirow{4}{*}{0.76} & -1.1 & 4.1 & \multirow{4}{*}{0.96} & -3.3 & 16.1 & & 0.04 & 0.16 & \\
\hline $38-50(29)$ & -0.4 & 6.7 & & -1.6 & 9.3 & & -1.2 & 4.5 & & -3.9 & 17.6 & 0.85 & 0.05 & 0.17 & 0.23 \\
\hline $51-70(25)$ & -0.8 & 7.9 & & -2.4 & 8.8 & & -1.5 & 3.1 & & -6.5 & 12.0 & & 0.03 & 0.14 & \\
\hline$>70(18)$ & -3.0 & 10.8 & & -4.3 & 9.4 & & -0.9 & 4.4 & & -5.9 & 13.2 & & 0.14 & 0.27 & \\
\hline Technical area§ & & & & & & & & & & & & & & & \\
\hline No (55) & -1.5 & 6.9 & & -3.2 & 8.5 & & -1.4 & 4.4 & & -6.2 & 17.0 & & 0.06 & 0.17 & 0.98 \\
\hline Yes (46) & -1.0 & 8.4 & 0.71 & -1.9 & 8.4 & 0.71 & -1.0 & 3.5 & 0.63 & -3.0 & 12.4 & 0.30 & 0.05 & 0.18 & \\
\hline Mechanical ventilation & & & & & & & & & & & & & & & \\
\hline No (64) & -1.0 & 6.4 & 0.45 & -2.4 & 7.7 & 0.81 & -1.4 & 4.1 & 0.26 & -4.7 & 16.0 & & 0.06 & 0.20 & \\
\hline Yes (29) & -2.3 & 9.7 & & -2.9 & 9.5 & & -0.4 & 3.7 & & -3.4 & 12.2 & 0.69 & 0.06 & 0.17 & 0.97 \\
\hline $\begin{array}{l}{ }^{*} \Delta: \% \text { predicted at the fin } \\
+F E V_{1} / F V C \text { at the final pl } \\
\ddagger \text { Methacholine dose-resp } \\
\text { log(slope+0.02). Change } \\
\S \text { Answer "no" correspon } \\
\text { "Answer "no" correspon } \\
\text { ventilation. }\end{array}$ & $\begin{array}{l}\text { - FEV } \\
\text { slope, } \\
\text { thacho } \\
\text { the abs } \\
\text { the pre }\end{array}$ & $\begin{array}{l}C \text { at } \\
\text { ed by } \\
\text { slope } \\
e \text { of a } \\
\text { ce of a }\end{array}$ & $\begin{array}{l}\text { efined } \\
\text { chnica } \\
\text { door o }\end{array}$ & $\begin{array}{l}\text { as log } \\
\text { al areo } \\
\text { or a wi }\end{array}$ & +0 & $\begin{array}{l}\text { at the } \\
\text { nce of } \\
\text { sence }\end{array}$ & $\begin{array}{l}\text { led by } \\
\text { final } \\
f \text { a non } \\
\text { of non }\end{array}$ & $\begin{array}{l}- \\
\text { ilate } \\
\text { ionir }\end{array}$ & $\begin{array}{l}\text { hulative } \\
\text { (slope+ } \\
\text { echnica } \\
\text { mechar }\end{array}$ & $\begin{array}{l}\text { dose o } \\
+0.02) \text { a } \\
\text { al area. } \\
\text { nical ver }\end{array}$ & $\begin{array}{l}\text { ethach } \\
\text { e initi } \\
\text { ation. }\end{array}$ & $\begin{array}{l}\text { line a } \\
\text { phase }\end{array}$ & $\operatorname{minis}$ & $\operatorname{expr}$ & ed as \\
\hline
\end{tabular}

chosen office work, as their future occupation would not involve exposure to such agents. The observed differences could not be explained by other personal factors: the sex distribution was not significantly different in the two groups; office apprentices were slightly younger than hairdressing apprentices; former and current smokers were more frequent among hairdressing apprentices. We chose office apprentices rather than university students as the control group, because they present a similar socioeconomic level to that of hairdressing apprentices. Although the training centres were located in different places, several hairdressing apprentices lived in the outskirts of Paris. There is therefore no reason to believe that the observed difference was related to the place of training.

In contrast, for the longitudinal study, only 191 of 297 subjects $(64 \%)$ participated in the questionnaire survey and 119 of 239 subjects $(50 \%)$ completed the lung function tests among hairdressing apprentices, versus $76 \%$ (189/248) and $61 \%(76 / 124)$, respectively, for office apprentices. A relatively large number of subjects were lost to follow up, especially in the hairdressing apprentices group. Additional subjects enrolled in the hairdressing apprentice group and in the office apprentice group for the final phase were slightly older, but did not differ significantly from the initial groups according to gender and smoking habits.

Comparison of the hairdressing apprentices participating in both phases of the study with those lost to follow up showed that subjects lost to follow up presented a higher prevalence of respiratory symptoms with a significant difference for wheezing and atopy (table 5). A similar pattern was observed in office apprentices for respiratory symptoms.

A selection bias was also suspected for lung function. Hairdressing apprentices had better lung function values than office apprentices at the initial examination. However, participation in lung function tests depended on group status, as $20 \%$ of subjects in the hairdressing group and $50 \%$ of the office apprentices did not participate in lung function tests. No difference in the frequency of respiratory symptoms was observed according to participation in lung function tests among hairdressing apprentices. It can therefore be assumed that lung function values of hairdressing apprentices were similar to those of the study population. In contrast, the office apprentices who participated in the lung function tests presented a higher frequency of wheezing and symptoms of mucosal hyperresponsiveness than the nonparticipants, suggesting that office apprentices with respiratory disorders preferred to have a respiratory check-up.

The lung function values of the office apprentices group were probably lower than the values that would have been observed if more subjects had participated. Moreover, hairdressing apprentices lost to follow up in the lung function study presented lower values for lung function tests than those participating in both phases, whereas no significant difference was observed between participants and subjects lost to follow up among office apprentices. These data suggest the presence of a healthy worker effect among hairdressing apprentices, although the study was unable to collect information about the reasons for leaving the apprenticeship. They are in accordance with the results reported by Leino and colleagues $^{11}$ in a study investigating the reasons for leaving the profession among Finnish hairdressers compared to commercial personnel during the period 1980-95. These authors found that the risk of leaving the profession for asthma or hand eczema was 3.5 times higher among hairdressers. Similarly, the study by Dosman and colleagues ${ }^{7}$ showed a differential drop-out of study subjects according to atopy status in cereal grain workers.

Despite this selective drop-out, we observed a deterioration of baseline lung function tests among hairdressing apprentices during follow up. BHR also appeared to increase in hairdressing apprentices and decrease in office apprentices, as reflected by methacholine slopes. The decreased percentage of BHR among office apprentices between the initial and final cross sectional phases could be an artefact, as it was 
mainly related to a low percentage of office apprentices with BHR among the subjects who only participated in the final phase (13.5\% of 38 office apprentices). Data from subjects who completed the longitudinal survey are therefore more convincing.

We observed significant differences between hairdressing apprentices and office apprentices in terms of the change in baseline lung function parameters. We should emphasise the fact that this variation was only slight and therefore probably has only limited clinical significance at the individual level, but this does not exclude the potential importance of these variations at the group level.

The difference observed between the two groups could have been influenced by the pattern of lung function change in the age categories concerned. As observed by Knudson and colleagues, ${ }^{8}$ lung function parameters tend to decrease after the age of 20 years in females and 25 years in males. These age limits affected some of the subjects in our study during follow up. We then conducted supplementary analyses. Further multivariate analyses did not show any effect of age category in the final phase on the change in baseline lung function values (data not shown). It is therefore unlikely that our results could be explained by a difference in the age distribution between hairdressing apprentices and office apprentices.

Because methacholine challenge was performed in schools, it was decided to stop the test if a $15 \%$ decrease in $\mathrm{FEV}_{1}$ was observed compared to the baseline value. This may have led to an overestimation of the number of subjects considered to have BHR, as a $20 \%$ decrease of $\mathrm{FEV}_{1}$ is the criterion generally adopted for this diagnosis. In contrast, the maximum dose of methacholine used in this study was $1500 \mu \mathrm{g}$, and this may have led to an underestimation of the true frequency of BHR. We therefore used two parameters to describe the results of methacholine challenge: the percentage of subjects with a $15 \%$ decrease in $\mathrm{FEV}_{1}$ and the dose-response slope. This last parameter is presumed to be less influenced by the procedure used in this study for interpretation of the results of methacholine challenge.

We examined the effect of occupational factors on changes in lung function tests among hairdressing apprentices. No significant association was observed between changes in lung function tests and frequency of exposure to persulphates (permanent waving, dyeing, bleaching) or the characteristics of hairdressing salons. This result was relatively unexpected, as previous studies have shown a relation between exposure to persulphates and incidence of asthma. ${ }^{312}$ However, a relatively small proportion of the subjects reported performing bleaching at least once a day $(50 \%)$ (table 6 ). On the other hand, the reported frequency of exposure could have been a poor indicator of inhaled dose, as many of the hairdressing salons were small (33\% of salons had a surface area less than $38 \mathrm{~m}^{2}$ ), suggesting the possibility of environmental exposure. The increased incidence of BHR in the hairdresser group in the longitudinal survey may reflect an effect of exposure to irritant materials as well as sensitisation, as some chemicals encountered by these apprentices exerted both properties (for example, persulphates).

A different distribution of smoking habits between the two groups with a higher frequency of former and current smokers in hairdressing apprentices could also be an explanation for the apparent worsening of lung function among hairdressing apprentices, although smoking status was taken into account in multivariate analyses. Cumulative smoking may have differed between the two groups, but smoking status was probably a good indicator of cumulative smoking due to the young age categories concerned.

Previous studies concerning hairdressers have shown relatively high prevalences of respiratory symptoms or respiratory disease, often significantly higher than those observed in control groups, such as office workers or sales personnel..$^{13-15}$ Most of these studies were cross sectional and did not specifically concern apprentices.

Leino and colleagues ${ }^{4}$ conducted a retrospective cohort study in 4433 female hairdressers in Finland. For the period 1980-95, the incidence of physician diagnosed asthma was 2.2 versus 1.3 per 1000 person-years and the incidence of chronic bronchitis was 1.1 versus 0.9 per 1000 person-years in hairdressers and in reference groups. The relative risk for developing asthma during the 15 year observation period was 1.7 (95\% CI 1.1 to 2.5 ) and that for chronic bronchitis was 1.2 (95\% CI 0.7 to 1.9 ).

In Sweden, the study by Albin and colleagues, ${ }^{16}$ focusing on the incidence of asthma in hairdressers, showed an incidence rate of 3.9 per 1000 person-years in active hairdressers versus 3.1 per 1000 person-years among referents during the period 1970-95.

To our knowledge, our study is the first to focus on early respiratory effects in hairdressing apprentices. The development of respiratory disorders during apprenticeship has been studied in other occupations. Gautrin and colleagues ${ }^{5}$ studied animal health technology apprentices during their training (three or four years) to investigate the development of sensitisation and disease due to high molecular weight allergens. The authors concluded that the incidence of sensitisation, symptoms, and diseases was maximal during the first 2-3 years after starting training.

Similarly, Kennedy and colleagues ${ }^{6}$ studied airway responsiveness in apprentices exposed to metalworking fluids compared to control subjects during a two year period. While machinists and controls did not differ at the baseline test, machinists showed a significantly higher level of mean change in bronchial responsiveness than controls at subsequent follow up.

These studies tend to suggest that respiratory disorders and/or sensitisation could occur early during apprenticeship. This underlines the interest of follow up studies in apprentices in occupations associated to exposure to respiratory sensitisers.

\section{CONCLUSION}

The two cross sectional phases of our study did not provide any clear evidence of work related respiratory effects in hairdressing apprentices compared to office apprentices, but suggested a strong healthy worker effect, at least at the beginning of the study. The main finding of the longitudinal survey of hairdressing apprentices and office apprentices is the deterioration of lung function in hairdressing apprentices compared to office apprentices, with no significant difference in the incidence of respiratory symptoms between the two groups. However, there was no evidence of a link between deterioration of lung function and specific occupational activities among hairdressing apprentices. As the data suggested the presence of a healthy worker effect, the impairment of several lung function tests observed in the hairdressing group could be considered to be an early indicator of a work related adverse health effect in hairdressing apprentices. Our study highlights the need for specific respiratory surveillance of hairdressing apprentices and further studies of working conditions and chemicals handled in this occupational group.

\section{ACKNOWLEDGEMENTS}

We would like to thank the following people for their contribution to this study: Prof ML Efthymiou; Drs M Aioutz, C Allanic, JF Aubart, MC Bayeux, C Becquet, MC Bouton, G Charlois, I Droulers, C Ginioux, N Guen, C Habert, E Hamel, A Hervé, M Hervé-Guillot, B Jeanvoine, C Joubrel, K Legrand-Cattan, R L'Huillier, S Makhloufi, JC Martin, D Pecqueur, E Perrigault, F Questel, G Riboulet-Delmas, F Roos, 
C Rosenblum, C Sasportes, R Sebbah, J Tell, C Voisin; Mrs J BayardJarigge, S Chamming's, A Lemercier, N Lissak, N Pierre; Mr L Chastaing, G Croatto, M Delfosse, R Fraisse, C Haggai, J Laureillard, G Rouchy.

\section{Authors' affiliations}

Y Iwatsubo, M Matrat, INSERM E03-37, Cretéil, France

J Ameille, D Choudat, F Conso, R Garnier, J C Pairon, Institute

Interuniversitaire de Médecine du Travail de Paris lle de France, Paris, France

C Hubert, $\mathrm{CHI}$ Créteil, France

P Brochard, Université Bordeaux2, Bordeaux, France

D Coulondre, CMTI, Paris, France

F Lauzier, CRAM-IF, Paris, France

M C Romano, Ministère de l'Education Nationale, Paris, France

Grant sponsor: This study was funded by the Caisse Régionale d'Assurance Maladie d'lle de France (CRAM-IF, Paris), Caisse Régionale des Professions Artisanales d'lle de France (St-Denis), and Mutuelle Nationale des Métiers (MNM, Paris)

\section{REFERENCES}

1 Ameille J, Pauli G, Calastreng-Crinquand A, et al. Reported incidence of occupational asthma in France, 1996-1999: the ONAP program. Occup Environ Med 2003:60:136-41.

2 Schwartz HJ, Arnold JL, Strohl KP. Occupational allergic rhinitis in the hair care industry: reactions to permanent waves solutions. J Occup Med 1990;32:473-5

3 Blainey AD, Ollier S, Cundell D, et al. Occupational asthma in a hairdresser salon. Thorax 1986;41:42-50.
4 Leino $\mathrm{T}$, Tammilehto $\mathrm{L}$, Paakkulainen $\mathrm{H}$, et al Occurrence of asthma and chronic bronchitis among female hairdressers. A questionnaire study. J Occup Environ Med 1997;39:534-9.

5 Gautrin D, Ghezzo H, Infante-Rivard C, et al. Natural history of sensitization, symptoms and occupational diseases in apprentices exposed to laboratory animals. Eur Respir J 2001;17:904-8.

6 Kennedy SM, Chan-Yeung M, Teschke K, et al. Change in airway responsiveness among apprentices exposed to metalworking fluids. Am J Respir Crit Care Med 1999:159:87-93.

7 Dosman JA, McDuffie HH, Pahwa P. Atopic status as a factor in job decision making in grain workers. J Occup Med 1991;33:1007-10.

8 Knudson RJ, Lebowitz MD, Holberg CJ, et al. Change in the normal maximal expiratory flow-volume curve with growth and aging. Am Rev Respir Dis 1983;127:725-34

9 O'Connor G, Sparrow D, Taylor D, et al. Analysis of dose-response curves to methacholine. An approach suitable for population studies. Am Rev Respir Dis 1987; 136:1412-17.

10 Statistical Analysis System, SAS Institute Inc. SAS/STAT user's guide, version 8. Cary, NC: SAS Institute Inc., 1999.

11 Leino T, Tuomi K, Paakkulainen H, et al. Health reasons for leaving the profession as determined among Finnish hairdressers in 1980-1995. Int Arch Occup Environ Health 1999;72:56-9.

12 Schwaiblmair M, Vogelmeier C, Fruhmann G. Occupational asthma in hairdressers; results of inhalation tests with bleaching powder. Int Arch Occup Environ Health 1997;70:419-23.

13 Leino T, Tammilehto L, Luukkonen R, et al. Self reported respiratory symptoms and diseases among hairdressers. Occup Environ Med 1997;54:452-5.

14 Slater T, Bradshaw L, Fishwick D, et al. Occupational respiratory symptoms in New Zealand hairdressers. Occup Med 2000;8:586-90.

15 Hollund $\mathrm{BE}$, Moen $\mathrm{BE}$, Lygre $\mathrm{SH}$, et al. Prevalence of airway symptoms among hairdressers in Bergen, Norway. Occup Environ Med $2001 ; 58: 780-5$.

16 Albin M, Rylander L, Mikoczy Z, et al. Incidence of asthma in female Swedish hairdressers. Occup Environ Med 2002;59:119-23.

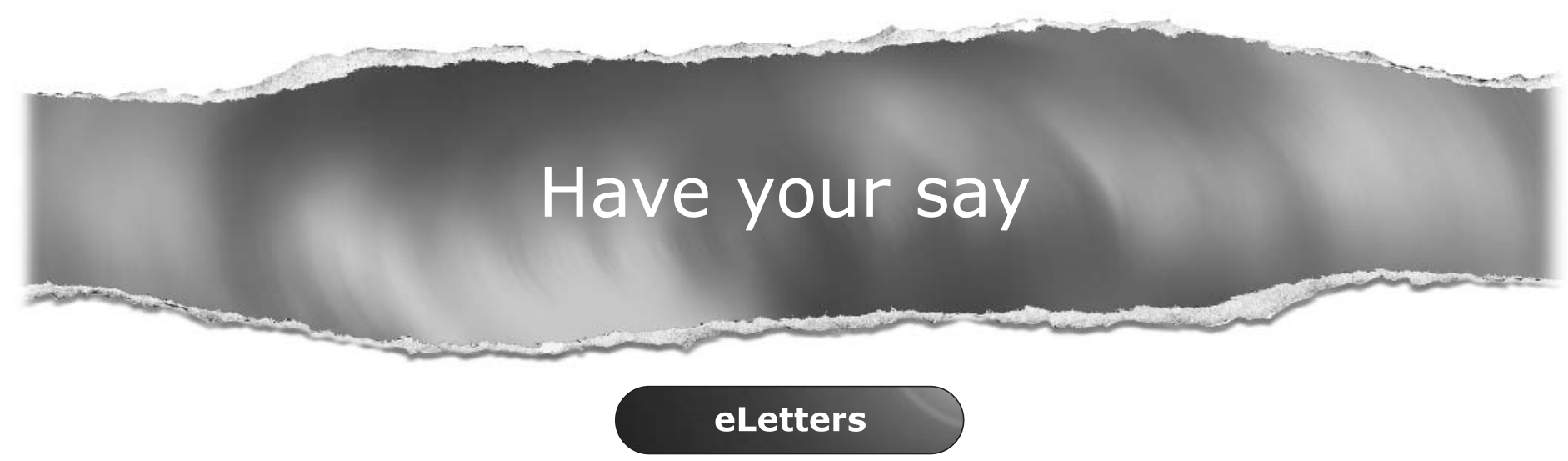

If you wish to comment on any article published in Occupational and Environmental Medicine you can send an eLetter using the eLetters link at the beginning of each article. Your response will be posted on Occupational and Environmental Medicine online within a few days of receipt (subject to editorial screening).

\section{www.occenvmed.com}

